\title{
A Convective Index as an Indicator of Cumulonimbus Development
}

\author{
W. K. SLY \\ Meteorological Service of Canada, Edmonton, Alberta
}

(Manuscript received 20 May 1966)

\begin{abstract}
Empirical methods are used to determine a modification to Jefferson's index of instability which has a good correlation with the incidence and development of cumulonimbus clouds over Edmonton, Alberta. This results in a convective index combining a representative afternoon dew point, the maximum temperature for the day and the temperature at the $500-\mathrm{mb}$ level at the time of maximum heating. A critical value for the incidence of cumulonimbus evolves. Field testing shows increased accuracy in cumulonimbus forecasting when a forecast index is used. The forecast index has been applied to other localities in western Canada and proved to be a useful tool in delineating areas of expected instability from the surface through the 500-mb level.
\end{abstract}

\section{Introduction}

Warm frontal activity being at a minimum throughout the western sections of Canada and the United States during the summer months, convective development becomes the main concern of the operational forecaster. The problem is met by a) estimating the state of the atmosphere as to temperature and moisture during the time of maximum heating to determine whether a state of unstable equilibrium will be reached and b) determining whether rising motion will take place causing saturation. The principal defect of this procedure is its vague qualitative approach. Since cumulus development is the visual evidence of the overturning of the atmosphere which may follow the establishment of an unstable lapse rate, a numerical correlation between observations of cumulus type clouds and the characteristics of the atmosphere as observed in, or forecast from, the early morning reports would add a quantitative step to the current qualitative procedures. The purpose of this study is to do this by showing that a) the elements usually considered by a forecaster in determining his forecast of clouds of vertical development (cumulonimbus) can be combined to form a simple numerical index which has a high correlation with the incidence of these clouds and b) the accuracy of forecasts of the incidence of cumulonimbus clouds is increased when based on the estimation of this index.

\section{Index}

Background. Along with factors contributing to rising motions, conditions of low level temperature

$\begin{array}{lrrrrrrr}T_{d 700} & 0 & 2 & 4 & 6 & 8 & 10 & 12 \\ m & +3 & +2 & +1 & 0 & -1 & -2 & -3\end{array}$

and moisture, mid-level moisture and upper level temperatures are the main elements considered by the forecaster in his qualitative analysis of the atmosphere. The representation of the above (with the exception of rising motions) in numerical form results in an instability index closely resembling that defined by by Boyden (1963). Many studies of stability have been made and several indices developed. Those of Showalter (1953) and Bailey (1955) are widely used. More recently Rackcliff (1962) developed an instability index for use in regional forecasting and this has been modified by Jefferson (1963a). In Jefferson's modification, an index of instability $I$ is calculated at 0000 GMT from the formula

$$
I=1.6 \theta_{w 900}-T_{500}-11,
$$

where $\theta_{w 900}$ is the wet-bulb potential temperature $\left({ }^{\circ} \mathrm{C}\right.$ ) at $900 \mathrm{mb}, T_{500}$ the $500-\mathrm{mb}$ temperature $\left({ }^{\circ} \mathrm{C}\right)$ and 11 is a correction factor to keep the threshold value for the occurrence of thunderstorm activity the same as that in Rackliff's formula (i.e., if $I$ is greater than 30 , thunderstorm activity is to be expected). This index is used to delineate areas where thunderstorm activity is likely the following day over the eastern Atlantic, Europe and the Mediterranean. It has been further modified by Jefferson (1963b) to take into account the effects of variations in the amount of midlevel moisture. If $T_{d 700}$ is the dew-point depression $\left({ }^{\circ} \mathrm{C}\right.$ ) at the $700-\mathrm{mb}$ level, and $m$ the correction, then the correction to $I$ is made according to the following table.

$\begin{array}{rrrrrrrr}14 & 16 & 18 & 20 & 22 & 24 & 26 & 28 \\ -4 & -5 & -6 & -7 & -8 & -9 & -10 & -11\end{array}$


Jefferson (196,3b) states allowances can be made for advection and surface heating in the calculation of $I$. Further, the formula is suitable for empirical testing as the contributing elements can be selected from levels other than those of the 900 - and 500 -mb surfaces. In this study Jefferson's formula is the basic one used to reduce stability conditions to a numerical form in order to correlate them with the incidence of cumulonimbus cloud.

Method. A good correlation between an index calculated from the early morning upper air sounding (1200 GMT) and the incidence of cumulonimbus cloud during the afternoon or evening would be ideal. This was investigated first. An index for the day was calculated from the 1200 GMT reports (no forecasting) and scatter diagrams constructed using observed convective cloud amounts as ordinates and values of the index as abscissae. As this correlation proved unsuccessful (see results below), the various elements that are combined to form the index were taken from the afternoon reports (forecasting), one at a time, and used to calculate new values of the index. Again scatter diagrams were plotted as above.

Synoptic experience indicates considerably more cloud of vertical development appears in the vicinity of a front than would otherwise be expected. The plotting on the scatter diagrams distinguished between frontal and nonfrontal days. A frontal day is defined as a day in which the weather at Edmonton was affected by a cold front (surface or upper) or a wave on a stationary front. No attempt was made to take into account the iritensity of the front.
Data. For reasons of control, both of the calculated index and the reports of observed weather, only conditions at Edmonton's Industrial Airport (72879-XD) were used. Upper air data were abstracted from the Monthly Bulletin, Canadian Radiosonde Data. Ascents are made at Edmonton at 0000 GMT (1700 MST, approximately the time of maximum heating during the summer) and 1200 GMT (0500 MST, near the time of maximum radiational cooling). Surface reports are from the Daily Weather Reporting Form 2322. Only convective development between 1100 and 2300 local time was considered. Reports of distant lightning and distant cumulonimbus tops were interpreted as a trace of cumulonimbus. The period of the study was 14 May to 31 August inclusive, 1962-4 (330 days).

Results. Details of the various elements and their combinations used in calculating the indices for the numerous trials mentioned above are contained in a technical paper by Sly (1964) and need not be discussed here. Each new combination of elements represents a modification of Jefferson's Index of Instability $I$, and the result will be referred to as a Convective Index $C$. After plotting the results of thousands of calculations, the following indices were found to have the best correlation with reports of cumulonimbus cloud over Edmonton:

$$
\begin{aligned}
& C=C_{1}=1.6 \theta_{w 12 m}-T_{500_{00}}-11, \\
& C=C_{2}=1.6 \theta_{w 21 m}-T_{500_{00}}-11, \\
& C=C_{3}=C_{2}+m_{00},
\end{aligned}
$$

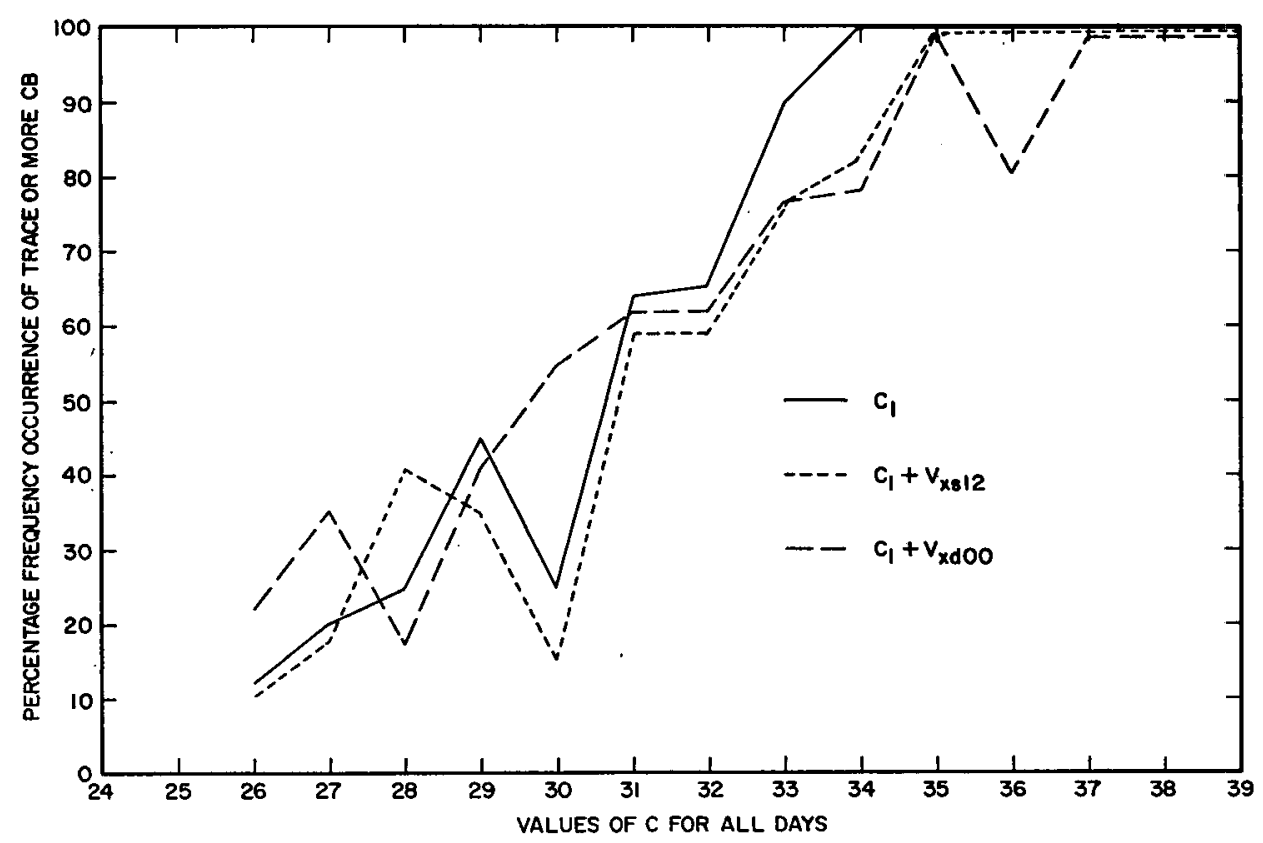

FIG. 1. Values of $C_{1}=1.6 \theta_{w 12 m}-T_{50000}-11$ are plotted against the incidence of cumulonimbus over Edmonton. The effects of 500-mb vorticity at Prince George (XS) for 1200 GMT and Edmonton (XD) for 0000 GMT are indicated by the dotted and broken lines, respectively. The period is 14 May to 31 August, $1962-4$. 


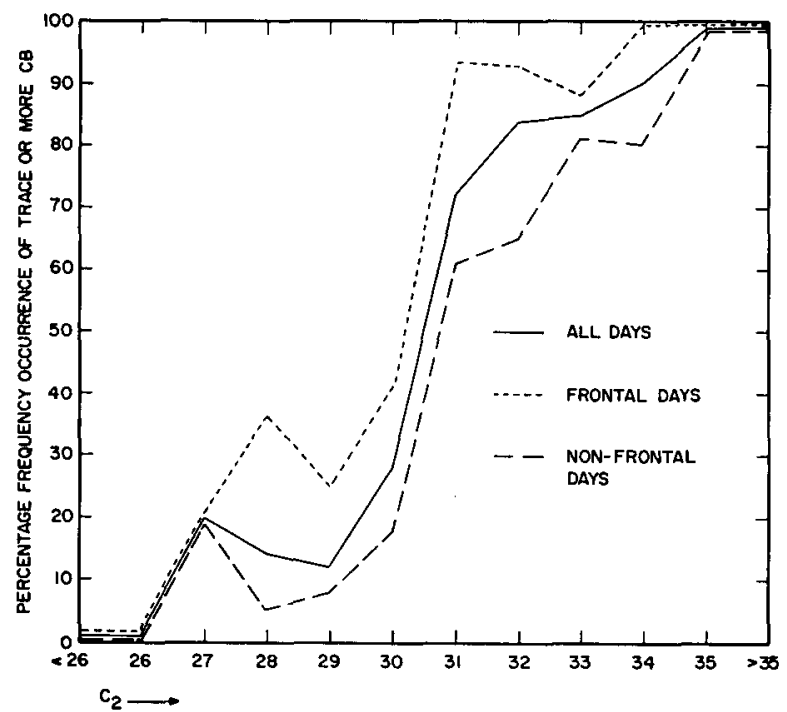

Fig. 2. Values of $C_{2}=1.6 \theta_{w 21 m}-T_{50000}-11$ for Edmonton are plotted against the percentage occurrence of a trace or more cumulonimbus for 14 May to 31 August, 1962-4. The solid line indicates all days, the broken line non-frontal days and the dotted line frontal days.

where $\theta_{w 12 m}$ is the wet-bulb potential temperature $\left({ }^{\circ} \mathrm{C}\right)$ calculated using the 1200 GMT dew point and the maximum for the day, $\theta_{w 21 m}$ is the wet-bulb potential temperature $\left({ }^{\circ} \mathrm{C}\right)$ calculated using the $2100 \mathrm{GMT}$ dew point and the maximum for the day, $T_{500_{00}}$ is the $500-\mathrm{mb}$ temperature $\left({ }^{\circ} \mathrm{C}\right)$ at 0000 GMT the following day, and $m_{00}$ is the correction due to mid-level moisture at 0000 GMT the following day. [See c) below.]

\section{Discussion of the best correlations.}

a) $C_{1}=1.6 \theta_{m 12 m}-T_{50000}-11$.

In this case only the maximum for the day and the $500-\mathrm{mb}$ temperature at approximately the time of maximum heating are forecast. From Fig. 1 it is seen that for $C_{1}<29$ or $>31$ this computation could be of value as an indicator of the incidence of cumulonimbus, but for the values in between a further refinement is necessary. This refinement is a forecast of the dew point occurring during the afternoon and leads to the second successful trial.

b) $C_{2}=1.6 \theta_{w 21 m}-T_{500_{00}}-11$.

In this case the late afternoon 500 -mb temperature and the maximum for the day are forecast along with a representative afternoon dew point. The 2100 GMT dew point was selected as being representative as it is not usually affected by convective shower activity.

The results of this trial are shown in Figs. 2 and 4. Fig. 2 shows the sharp increase in the incidence of cumulonimbus as the value of $C_{2}$ goes above 31. For $C_{2}>31.0$, percentage occurrences are so great that a forecast of cumulonimbus should be considered even if no frontal activity is expected. As $C_{2}$ drops below 31.0 , the percentage occurrences drop off rapidly and a forecast of cumulonimbus should not be considered unless frontal activity is expected, and then only under favorable synoptic conditions with the index greater than 28. Fig. 4 shows the cumulative totals of the various amounts of cumulonimbus clouds for $C_{2}$ greater than and less than 31 .

c) $C_{3}=C_{2}+m_{00}$.

In some instances in western Canada cumulonimbus cloud is observed even though upper air soundings indicate very dry air in the mid-levels. Under these conditions Jefferson's adjustment (see Section 2) weighs mid-level moisture too heavily. Trial and error showed the following table for moisture correction gave better results for this study.

$\begin{array}{lrrrrrrr}T_{d 700} & 0,1 & 2,3 & 4,5 & 6,7 & 8,9 & 10-15 & 15+ \\ m & +3 & +2 & +1 & 0 & -1 & -2 & -3\end{array}$

Here $T_{d 700}$ is the dew-point depression at $700 \mathrm{mb}$ and $m$ the correction to $C$.

Fig. 3 shows that, as an indicator of the incidence of cumulonimbus cloud, $C_{2}$ is slightly superior to $C_{3}$. In comparing the cumulative totals as shown in Figs. 4 and 5 , it is seen that $C_{3}$ is superior as an indicator of the development of broken cumulonimbus for values greater than 32 . The number of cases drops off rapidly after the index climbs above 33 and the smallness of the sample detracts from the significance of this feature. However, the results here support the observation of Austin (1948) that convective development is, in part, dependent on the moisture content of the entrained air.

Vorticity. Longley and Thompson (1965) found a

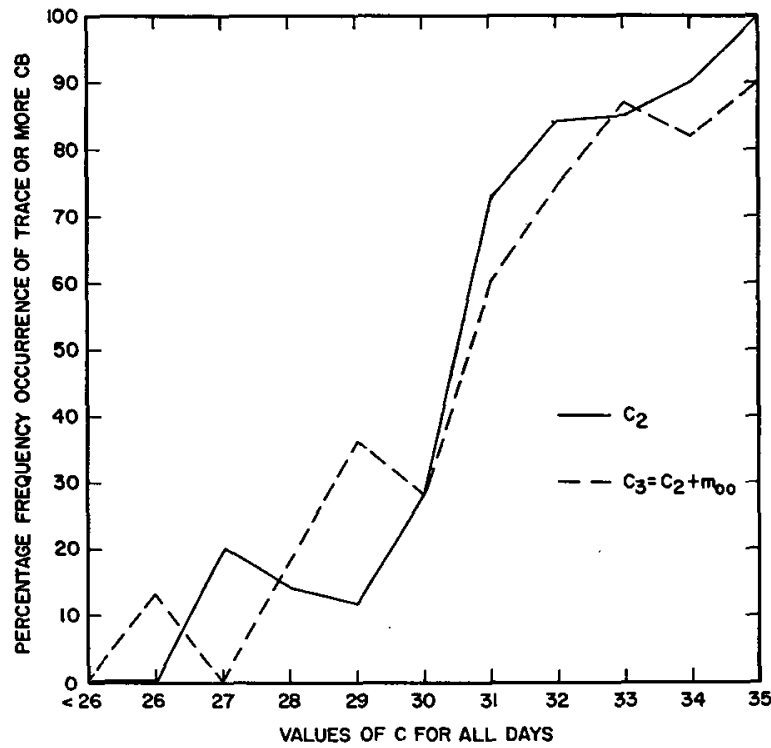

FIG. 3. Values of $C_{3}=C_{2}+m_{00}$ for all days are compared with values of $C_{2}$ as an indicator of the incidence of cumulonimbus cloud over Edmonton during 14 May to 31 August, 1962-4. 


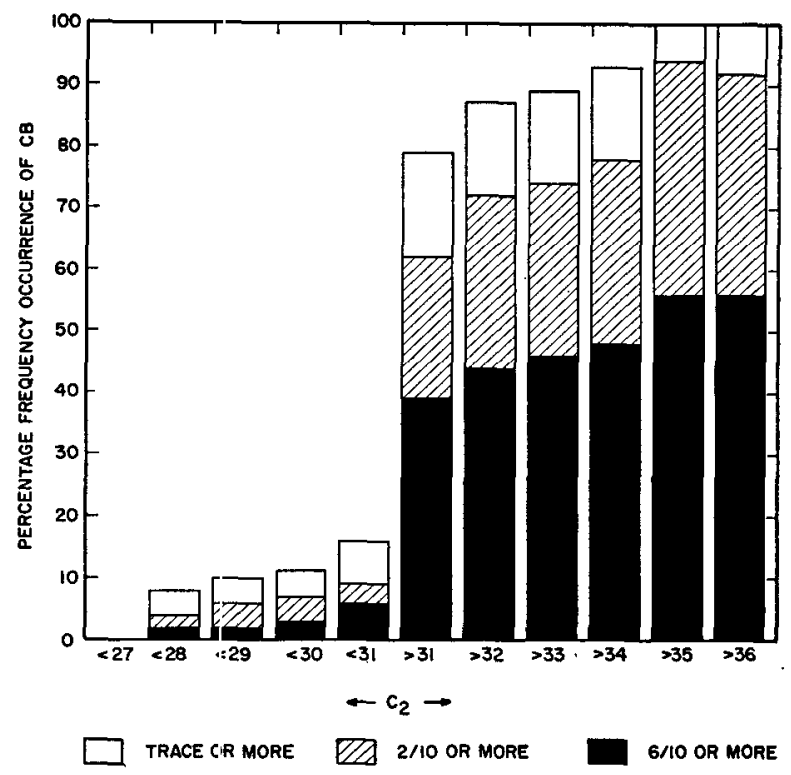

Fig. 4. Cumulative totals for the amount of cumulonimbus for all days are plotted against values of $C_{2}$ greater or less than 31 for 14 May to 31 August, 1962-4.

correlation between the incidence of hail in central Alberta and an approximation to the vorticity over British Columbia calculated from the 1200 GMT $500-\mathrm{mb}$ chart. To make the measure objective the heights of the $500-\mathrm{mb}$ surface at Annette Island (ANN), Fort Nelson (YE), Edmonton (XD) and Seattle (SEA) were acided and four times the height at Prince George (XS) subtracted from the sum. They found a similar relation existed with the relative vorticity over Edmonton calculated from the 0000 GMT $500-\mathrm{mb}$

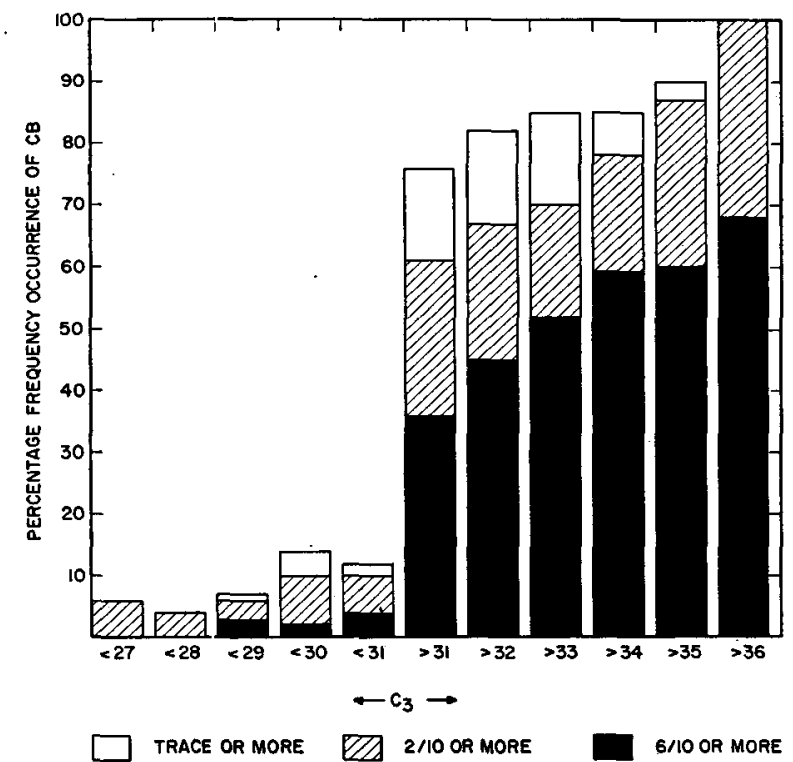

FIG. 5. Cumulative totals for the amount of cumulonimbus for all days are plotted against values of $C_{3}$ greater or less than 31 for 14 May to 31 August, 1962-4. chart in the same manner as before, using the heights at Prince George, Great Falls (GTF), Prince Albert (PA-estimated) and Fort Smith (SM). These figures were used as a basis for a correction to the index $C$. The figure obtained by expressing the vorticity as calculated, in hectometers, gave corrections of the same order as those for mid-level moisture (i.e., +4 to -4 ) and two scatter diagrams were made using this correction to $C_{1}$. The results are shown in Fig. 1 where $V_{x s 12}$ represents the correction to the index due to the 1200 GMT $500-\mathrm{mb}$ vorticity over Prince George and $V_{x d_{00}}$ the correction to the index due to the 0000 GMT $500-\mathrm{mb}$ vorticity over Edmonton. No increase in the percentage occurrences resulted and consideration of this type of adjustment to the index was abandoned.

Relation of the index to the thermodynamic chart and its generalization. If $\theta_{w 21 m}=10 \mathrm{C}$ and $T_{500_{00}}=26 \mathrm{C}$ are substituted in the formula $C_{2}=1.6 \theta_{w 21 m}-T_{50000}-11$, then $C_{2}$ becomes 31 . Plotting this information on a thermodynamic chart shows that $-26 \mathrm{C}$ is the temperature at which the $10 \mathrm{C} \theta_{w}$-line cuts the $500-\mathrm{mb}$ level. Under these conditions a parcel of air lifted from the ground is in neutral equilibrium with respect to the 500 -mb surface. The $20 \mathrm{C}$ wet-bulb potential temperature line cuts the $500-\mathrm{mb}$ level at $-9 \mathrm{C}$. Substituting these in the formula gives $C_{2}=30$. At Edmonton and most localities in western Canada, wet-bulb potential temperatures as calculated for this study as usually greater than $10 \mathrm{C}$. This means that an index greater than 31 indicates a parcel of air lifted from the surface will move freely through the 500-mb level (except for the rare cases mentioned in Section 8), and the greater the wet-bulb potential temperature contribution to the given index, the greater is the instability represented. This feature of the index is in accord with the study by Feteris (1965). He found that the threshold value of $\Delta T$ for the occurrence of thunderstorms increases as the 1000 -mb wet-bulb potential temperature increases. ${ }^{1}$

This study has indicated the percentage occurrence of cumulonimbus to be expected at Edmonton for various values of the index. As radar and pilot reports of cumulonimbus are scarce in this area no attempt was made to use reports of clouds other than those of the ground observers at Edmonton. Subsequent studies (Sly, 1965 a, b) of areas where a fine network of observations was available have given strong indications that when the convective index is greater than 31 , cumulonimbus development is nearly always in the immediate area. The above suggests that the forecast convective instability for various localities in the western sections of Canada and the United States could be conveniently expressed in numerical form and used to delineate areas of probable cumulonimbus development.

${ }^{1} \Delta T$ is the difference in temperature between the free air $500-\mathrm{mb}$ temperature and the temperature at which the moist adiabat through the $1000-\mathrm{mb}$ wet-bulb potential temperature cuts the 500-mb level. 


\section{Testing the index under operational conditions}

Method. The index was devised late in 1963 and the spring and summer of 1964 presented the first opportunity to test its value in the preparation of routine forecasts. As meteorologists' time in a forecast office is at a premium, it was decided to predict only the index that gave the best correlation with the incidence of cumulonimbus cloud over Edmonton, namely, $C_{2}=1.6 \theta_{w 21 m}-T_{500_{00}}-11$. The forecast of the various elements combined to give the index was made between 0900 and 1000 GMT. As forecasters were already studying conditions of stability, the additional time required to come to a firm decision as to actual temperatures and dew points to be forecast was usually only a few minutes. It should be noted here that the $500-\mathrm{mb}$ temperature forecast was for 24 hours as it was based on the 0000 GMT charts of the previous evening. A forecast of the index was made daily from 14 May through 31 August.

Results. In Fig. 6 the actual and forecast values of $C_{2}$ for all days are plotted as abscissae against the percentage frequency occurrence of the incidence of cumulonimbus as ordinates. The dips in the curves for the larger values of the index can be attributed to the comparatively small number of cases as the data is for one year only. For values of $C_{2}<30$, the forecast value was nearly as effective as the actual $C_{2}$ as an indicator of no cumulonimbus. For values of $C_{2}>30$, the actual $C_{2}$ was about 20 per cent better as an indicator of cumulonimbus development. Figs. $7 \mathrm{a}$ and $7 \mathrm{~b}$ show the results in cumulative totals for 1964 for both the actual and forecast values of $C_{2}$ and indicate the forecast values come well within the limits required for usefulness in operational work.

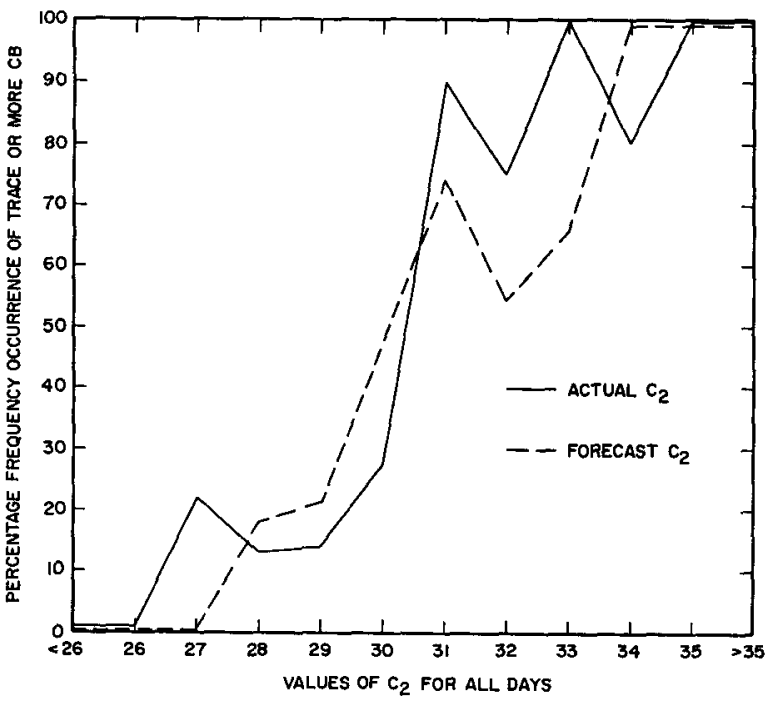

FIG. 6. The acutal value of $C_{2}$ for all days 14 May to 31 August, 1964, are compared with the forecast values for the same period.
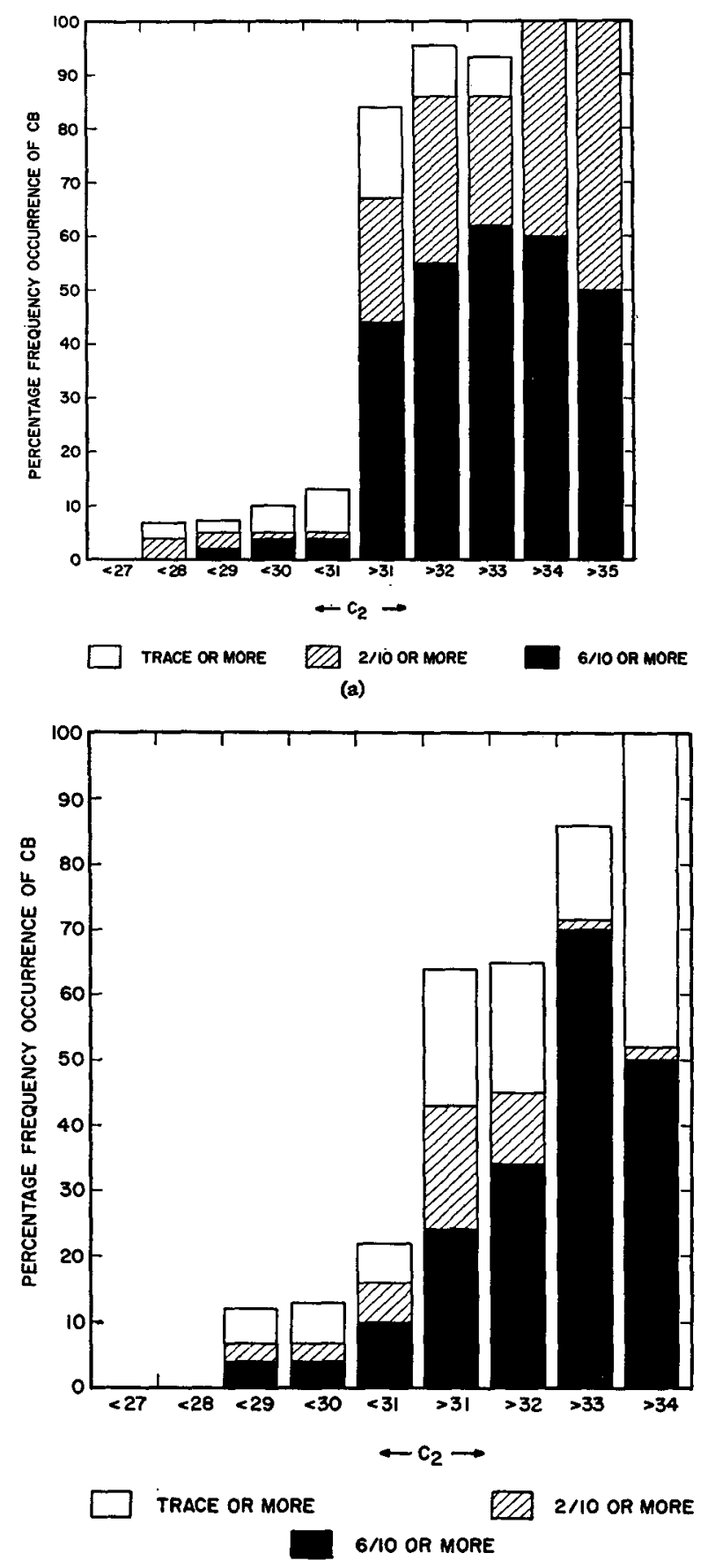

(b)

Fig. 7. Cumulative totals for the amount of cumulonimbus for actual values of $C_{2}$ greater or less than 31 for 14 May to 31 August, 1964, (a) are compared with the totals for values of the forecast $C_{2}$ for the same period (b).

\section{Effects on forecasts of cumulonimbus}

The entire period (1800-0600 GM'T) for which the index is to be used as a forecast aid is included in the 24-hr terminal forecasts for Edmonton issued in the early morning (1030 GMT). The best way to determine 
the effects of forecasting the index would be a comparison of the development of cumulonimbus indicated in these forecasts for 1964 (when the index was used) with the development forecast in previous years. Unfortunately, the 24-hr terminal forecasts for previous years have been destroyed and the only forecasts available for comparison are those issued at 1200 GMT (valid until 2400 GMT) and 1800 GMT (valid until 0600 GMT) for 1963 and 1964.
In the following table, it is assumed that some cumulonimbus would be forecast whenever the convective index $C_{2}$ is greater than or equal to 31,109 days being included. ${ }^{2}$ Since the figures in the columns opposite "Forecast $C_{2}$ (at 1000 GMT)" do not coincide with those opposite " $1200 \mathrm{Z}$ forecasts (1964)," it follows that forecasters used the forecast index only as a guide and not as the sole indicator of cumulonimbus development.

\begin{tabular}{|c|c|c|c|c|c|c|}
\hline & $\begin{array}{l}\text { No. of times } \\
\mathrm{Cb} \text { forecast } \\
\text { but did } \\
\text { not occur }\end{array}$ & $\begin{array}{l}\text { No. of times } \\
\mathrm{Cb} \text { occurred } \\
\text { but not } \\
\text { forecast }\end{array}$ & $\begin{array}{l}\text { Overall per } \\
\text { cent correct } \\
\text { forecasts of } \\
\mathrm{Cb} \text { or no } \mathrm{Cb}\end{array}$ & $\begin{array}{l}\text { No. of times } \\
\mathrm{Cb} \text { forecast } \\
\text { and occurred }\end{array}$ & $\begin{array}{l}\text { No. of times } \\
\mathrm{Cb} \text { occurred }\end{array}$ & $\begin{array}{l}\text { Per cent time } \\
\mathrm{Cb} \text { forecast } \\
\text { and occurred }\end{array}$ \\
\hline Actual $C_{2}(1.964)$ & 5 & 10 & 86 & 36 & 46 & 78 \\
\hline $\begin{array}{l}\text { Forecast } C_{2} \\
\quad(\text { at } 1000 \text { (GMT 1964) }\end{array}$ & 15 & 14 & 73 & 32 & 46 & 70 \\
\hline $\begin{array}{l}1200 \text { GMT forecasts } \\
\text { (1963) }\end{array}$ & 12 & 26 & 65 & 15 & 41 & 37 \\
\hline $\begin{array}{l}1200 \text { GMT forecasts } \\
(1964)\end{array}$ & 10 & 18 & 74 & 18 & 36 & 50 \\
\hline $\begin{array}{l}\text { 1800 GMT forecasts } \\
(1963)\end{array}$ & 8 & 22 & 72 & 33 & 55 & 60 \\
\hline $\begin{array}{l}1800 \mathrm{GMT} \text { forecasts } \\
(1964)\end{array}$ & 10 & 19 & 73 & 27 & 46 & 59 \\
\hline
\end{tabular}

The table shows that the 19641200 GMT forecasts of cumulonimbus occurrences were superior in every respect to those of 1963 . The overall percentage of correct forecasts of cumulonimbus or no cumulonimbus was up from 65 to 74 , and the percentage of the times cumulonimbus was forecast and occurred was up from 37 to 50 . This is all the more significant when combined with the figures in the first column above. They show a decrease in the over-forecasting of cumulonimbus (down from 12 times in 1963 to 10 in 1964). Also, it should be noted that a purely objective use of the index would have given a percentage accuracy increase from 37 in 1963 to 70 in. 1964, in the times cumulonimbus would have been forecast and occurred. Although it is dangerous to draw firm conclusions from one year's use, ${ }^{3}$ Edmonton forecasters are agreed that the improvement in cumulonirnbus forecasting shown above was due to the index and the interpretation of the result.

A new estimate of the index before issuing the 1800 GMT forecast was not part of the test program, and in general, since the original index was forecast by another man six hours previously, it was ignored. The figures in the last two rows of the table show that the

2 Smoke prevented the observations of cloud on one day and one 1200 GM' ' forecast was missing in 1964 reducing the number of days in that row to 108 .

3 The test is continuing in 1965. The index has been accepted and is estimated before both the 1200 and 1800 GMT forecasts. At the time of writing (15 August) $\mathrm{Cb}$ has been forecast at 1200 GMT on over 70 per cent of the days on which it has occurred and the 1800 GMT forecasts of cumulonimbus are running over 80 per cent in accuracy. accuracy of the 1963 and 19641800 GMT forecasts of cumulonimbus were nearly the same. However, had the forecaster preparing the 1800 GMT forecast accepted the value of the index as estimated at 1000 GMT as the basis of his cumulonimbus forecast, he would have had the same overall percentage accuracy (73) while improving his score of cumulonimbus forecast (when occurring) from 59 to 70 per cent.

\section{Bias in the forecast index}

Both the 1200 and 1800 GMT forecasts seriously underestimated the development of cumulonimbus. A forecast based on the estimated index in 1964 would have cut the number of times cumulonimbus would occur without being forecast to 14 . It would also increase the number of times cumulonimbus would be forecast and not occur to 15 , the largest number of all in the first column in the table above. This means that the index was being forecast too high on these occasions. Analysis of the forecasts of $\theta_{w 21 m}$ and $T_{500_{00}}$ shows that, in general, forecasts of $\theta_{w 21 m}$ were quite adequate (too high on 37 days for a total error of $41 \mathrm{C}$, too low on 34 days for $41.5 \mathrm{C}$ and correct the remaining 39 days). An over-estimated maximum temperature was usually accompanied by an under-estimated dew point. Forecasts of $500-\mathrm{mb}$ temperatures proved less satisfactory. $T_{500_{00}}$ was estimated too high on 30 days for a total of $56 \mathrm{C}$, correct on 22 days but too low on 57 days for $116 \mathrm{C}$. This definite bias to the cold side gave indices too high which, when occurring in the critical range of 
nearly neutral equilibrium, would contribute to the over-forecasting of cumulonimbus. Assuming a correct forecast of $T_{500_{00}}$ and using the $\theta_{w 21 m}$ as forecast during the summer of 1964, the overall accuracy of cumulonimbus or no cumulonimbus forecasts would have been up to 78 per cent. Other parameters being established, an accurate forecast of the temperature at the $500-\mathrm{mb}$ level is vital to the forecast of cumulonimbus development, particularly under conditions of nearly stable equilibrium.

\section{Expanded use of the forecast index}

Forecasting the convective index was begun 14 May. By 1 July, it was considered of sufficient use in the preparation of the $1200 \mathrm{GMT}$ forecasts that forecasters agreed additional indices should be estimated for other terminals in the district. Although this expansion was an entirely voluntary procedure and done only for those terminals for which it was considered necessary on any one day, indices for an average of ten terminals per day from 1 July to 31 August were estimated. The original study dealt with the relationship between the convective index and cumulonimbus clouds at Edmonton only. Forecasters found that by estimating the index at various points they had a very useful way of delineating the areas in the forecast district where instability from the surface through the $500-\mathrm{mb}$ level would most likely develop during the day. In nearly all cases it was found advisable to forecast convective cloud development and shower activity in those areas with a forecast convective index greater than 31 .

The application of the index to other areas of western Canada and the northwestern United States is under investigation and its prognostication by graphical methods is being tested.

\section{Other advantages of computing the index}

Consistency. Convective cloud formations will be consistent with forecasts of temperature and low-level moisture.

Estimation of temperatures at the 500-mb level. After a wet-bulb potential temperature has been determined from observed data, a critical $500-\mathrm{mb}$ temperature for the development of cumulonimbus can be determined. Cloud observations will indicate whether this critical temperature has been reached. This has obvious use in determining advection and in the placing of isotherms on the 0000 GMT $500-\mathrm{mb}$ chart in western time zones.

Determination of continued convective development. Conversely to the above, once the late afternoon wetbulb potential temperature has been established, the critical $500-\mathrm{mb}$ temperature for instability can be determined. Inspection of the isotherm pattern at the $500-\mathrm{mb}$ level will determine whether this critical temperature will be reached (i.e., whether the afternoon cumulus will build to cumulonimbus during the early evening or flatten out and dissipate).

Determination of the effects of departures of the components of the index from their forecast values. Once a late afternoon $500-\mathrm{mb}$ temperature has been estimated for a terminal, progress towards instability through the $500-\mathrm{mb}$ level can be determined by calculating a wet-bulb potential temperature from the hourly observations and substituting in the formula for $C_{2}$. A continuous hourly check on changes in surface temperature and dew point will indicate their departures from forecast values. The effect of these departures on the development of cumulonimbus can then be determined. This procedure is not limited to stations with upper air soundings. Local influences are reflected in the observations.

\section{Subjective assessment of the failures}

Studies of the failures of the index as an indicator of the incidence of convective cumulonimbus indicate nearly all can be attributed to one or more of the following:

a) Marked increase or decrease in dew point after 2100 GMT

b) Occurrence of lowest $500-\mathrm{mb}$ temperature at a time other than 0000 GMT.

c) Existence of a nose of warm air below the $500-\mathrm{mb}$ level creating a cap through which the updrafts do not penetrate.

d) Intensity of frontal activity.

e) Lack of identification of the cases when cirrus and altocumulus are the tops of cumulonimbus clouds, or when cumulonimbus is obscured by other clouds.

If a) and b) are taken into account when the index is being predicted, correct forecasts of the index will have better correlations with the incidence of cumulonimbus cloud than those found in this objective study. The effects of c) and d) can be considered in the usual manner. Further, since the index is based on the parcel theory, instances of failure which cannot be attributed to the reasons listed above would not be avoided using more conventional forecasting methods.

\section{9. $C_{1}$ and $C_{3}$}

These indices are not normally used. During this study it was noted on 54 per cent of the days considered that the 1200 GMT dew point at Edmonton was within $2 \mathrm{~F}$ of that at 2100 GMT. No doubt this feature contributes to the value of $C_{1}$ as an indicator of the incidence of cumulonimbus over Edmonton. Additional studies ${ }^{4}$ have shown that similar dew point relationships do not exist at other points in Alberta

\footnotetext{
${ }^{4}$ Johnson, L. W., 1965: Comparison of 1200 and 2100 GTM dewpoints at selected localities in western Canada. Unpublished.
} 
and western Saskatchewan. This indicates percentages for $C_{1}$ determined for Edmonton may not apply elsewhere.

$C_{3}$ has been used to advantage on several occasions but the difficulty in assessing the mid-level moisture pattern for sufficient time in the future makes its routine use of doubtful value.

\section{The $500-\mathrm{mb}$ temperature}

As measurements of temperatures at the 500 -mb level are taken only twice daily, adjustments to the forecast index due to changes aloft normally cannot be made. This emphasizes again the importance of accurate 500-mb temperature forecasts. As low-level conditions are measured hourly, it has been suggested that the use of the index would be simplified by applying a conversion factor to the $500-\mathrm{mb}$ temperature instead of the wet-bulb potential temperature. This, with the dropping of the constant 11 , would reduce the value of the index to zero for neutral equilibrium. Unfortunately, much of the advantage of this procedure is eliminated by the necessity of a different conversion factor for each 500-mb temperature. Further, the desired gain in instability for higher wet-bulb potential temperatures as built into the form of the index developed in this study would be lost.

\section{Conclusions.}

This study has shown that:

a) Moisture and temperature conditions at the surface can be combined with the temperature at the $500-\mathrm{mb}$ level in such a way that the numerical result has a high correlation with the incidence of cumulonimbus cloud over Edmonton.

b) The convective index $C_{2}$ (modified Jefferson) resulting from the above combination can be forecast with sufficient accuracy to be useful in operational work.

c) Forecasts at Edmonton based on the forecast of the convective index $C_{2}$ during the spring and summer of 1964 led to more accurate forecasts of cumulonimbus development.

d) A forecast of the convective index $C_{2}$ for various localities is a convenient way of delineating areas of expected instability from the surface through the 500 -mb level.

e) Mid-level moisture can be combined with the convective index $C_{2}$ to give a better indication of the probability of broken cumulonimbus over Edmonton.

f) An accurate $500-\mathrm{mb}$ temperature forecast is necessary for the prediction of cumulonimbus development under conditions of nearly neutral equilibrium.

Acknowledgments. Appreciation is expressed to the forecast staff at the Edmonton Weather Office for their willing cooperation in this study.

\section{REFERENCES}

Austin, J. M., 1948: A note on cumulus growth in a nonsaturated environment. $J$. Meteor., 5, 103-107.

Bailey, R. E., 1955 : Local thunderstorm forecasting, development of practical short range weather prediction techniques. Vissher, H. B., et al., Eastern Air Lines, Atlanta, Georgia, 51-61.

Boyden, C. J., 1963: A simple instability index for use as a synoptic parameter. Meteor. Mag., 92, 198-210.

Feteris, P. J., 1965: Statistical studies on thunderstorm situations in the Netherlands. $J$. Appl. Meteor., 4, 178-185.

Jefferson, C. J., 1963a : A modified instability index. Meteor. Mag., 92, 92-96.

- $1963 \mathrm{~b}$ : A further development of the instability index. Meteor. Mag., 92, 313-316.

Longley, R. W., and C. E. Thompson, 1965: A study of the causes of hail. J. Appl. Meteor., 4, 69-82.

Rackliff, P. G., 1962: Application of an instability index to regional forecasting. Meteor. Mag., 91, 113.

Showalter, A. K., 1953: A stability index for thunderstorm forecasting. Bull. Amer. Meteor. Soc., 34, 250-252.

Sly, W. K., 1964: A convective index as a forecast parameter. Canada, Department of Transport, CIR. 4087 TEC 531, $14 \mathrm{pp}$.

_ $1965 \mathrm{a}:$ A convective index in relation to lightning strikes in northwestern Alberta. Canada, Department of Transport, CIR 4220 TEC 566, $11 \mathrm{pp}$.

- 1965b: A convective index in relation to hail in central Alberta. Canada, Department of Transport, CIR 4240 TEC $573,30 \mathrm{pp}$. 